\title{
Examining the Effective Factors on Spectators' Attendance in Volleyball World League in Iran
}

\section{Doi:10.5901/mjss.2016.v7n4s1p155}

\author{
Mehrdad Manouchehri ${ }^{1}$ \\ Ghasem Manouchehri2 \\ Seyyed Ahmad Mehrian ${ }^{3}$ \\ Omid Zafarmand 4 \\ ${ }^{1}$ Master of Sport and exercise management \\ ${ }^{2}$ Master of Sport and exercise management \\ ${ }^{3}$ Master of Exercise physiology \\ ${ }^{4}$ Master of Exercise physiology
}

\section{Abstract}

The purpose of the current study was to investigate the effective factors affecting the spectators' attendance in Volleyball World League in Iran. The statistical population of the study included the whole spectators who attended in Volleyball World League in Iran. This research was an applied descriptive survey. The questionnaire used in this study was developed by Green (1995), Hansen and Gauthier (1989), Schofield (1983), Kaskey (1994), and Zhang et al. (1995) for sports played with a ball in order to examine factors affecting spectators' attendance in Volleyball World League in Iran. The questionnaire was modified by the researcher and the effect of the spectators' attendance at volleyball halls were evaluated with 31 items in 4 scopes including economics, game attractiveness, spectators' preferences and facilities. After determining the sample size, the questionnaires were distributed among 100 spectators attended at volleyball hall via random sampling. The reliability of the questionnaire was obtained through Cronbach's Alpha as 0.86 in a preliminary study. In order to analyze the data, one-variable $T$ and $F$ tests were used. The results demonstrated that the three factors of game attractiveness, spectators' preferences and the availabilities of facilities had a positive effect on spectators' attendance and only the economic factors had negative effect on spectators' attendance at volleyball halls. Among economic factors, the reasonable ticket price of tournaments; among game attractiveness factors, the presence of star players in favorite team; among the spectators' priorities, the proper holding of the volleyball world league tournaments; and among facilities factors, easy arrival and departure without any time-consuming from the halls and parking lots had the effects on spectators' attendance in halls.

Keywords: Professional Sport, Spectators, Volleyball, Business, World League

\section{Introduction}

Sport has made its way into the field of knowledge, economy, and art by introducing the new social values. The obvious and hidden attractions of this evolution have caused the arousing of emotions and the creation of certain tendencies among all communities against sport events (1). In the field of world business, sport is exceptional because it has customers who pay money not for buying or using sport but for watching it (6). Of the activities related to the sport, watching sport tournaments can be mentioned where thousands of enthusiastic people attend. The spectators' attendance at sport events and that these spectators consist of various strata of society including men and women, young and old, different races and ethnic groups, are evidences of this claim. Nowadays, the spectators in sport constitute an important percent of sport consumers (3). Patton and Burlington (2004) reported that factors such as availability of recreational activities in the stadium, the reasonable price and ticket distribution practices, proper weather, stadium design, and the availability of facilities have the most effect on the attendance of soccer spectators in the university soccer league in the America region 1 in the stadiums (9). Haward and Crampton (1995) stated that 41 percent of the total revenue of America Basketball League, 59 percent of the total revenue of National Hockey League in America, and 22.8 percent of the total revenue of National Soccer League are obtained through ticket sales (2). Among the sports, soccer is undoubtedly the most popular, the most watched and the most exciting sport in the world and our country, Iran, isn't either free from it (2). In their study, Levine and McDonald (2009) found that the accessibility of the sport facilities has been a component of important factors for spectators (4). Fallahi et al. (1388) showed that the economic factors (ticket price and the cost of traffic) and stadium facilities are of the most important factors affecting the spectators (8). In fact, since 1970 up to now, these studies have been conducted continuously and in many societies they are still 
performed. Another remarkable point in this study is that although the issue of spectators and the factors affecting them has been able to have many research attractions abroad in different fields such as sport management, psychology, sociology, and economics, they have not been considered so much in Iran. In fact, some studies have been conducted in Iran in which football has been more considered and less attention has been paid to other sport fields. But, the present study has been done with the aim of examining the effects of various factors such as economic, charm of the game, spectator preferences and facilities on volleyball spectators' attendance in volleyball halls. It is assumed that these factors have a relative effect on spectators' decision to attend the halls and watch the volleyball tournaments from nearby. The sports officials of the country and clubs must be able to properly maintain this national capital and with knowledge of these factors and with a strategic planning, they could provide the conditions for more attendance of the audiences in the halls. They can also provide such circumstances in a wider geographical area by using right tools having appropriate validity and reliability. With regard to the performed works, this study scrutinizes the effective factors influencing audiences' attendance in volleyball world league and attempts to find whether these factors have any effect on the audiences' attendance or not. Can spectators' attendance in the halls be effective in the volleyball tournaments? Thus, the purpose of this research is the impact of effective factors on the spectators' attendance in volleyball world league. In this research, we want to know whether spectators' attendance in volleyball world league as an independent variable will have any significant effect on the Iranian Volleyball players as a dependent variable or not.

\section{Methodology}

The current study investigates the impact of effective factors on the spectators' attendance in volleyball world league in Iran. The main design of this research is descriptive survey method. The statistical population of the present study consisted of the total spectators who attended the volleyball world league in Iran. After determining the sample size, the questionnaires were distributed among 100 spectators in volleyball hall using random sampling. In order to collect the data, the researchers utilized a questionnaire developed by Green (1995), Hansen and Gauthier (1989), Schofield (1983), Kaskey (1994), and Zhang et al. (1995) for sports played with a ball in order to examine factors affecting spectators' attendance in Volleyball World League in Iran. The researchers made some modification in the questionnaire to adjust it with the Iranian spectators. The questionnaire is divided into two sections the first part of which consists of 31 questions with five-Likert Scale (Strongly Agree, Agree, Neither agree nor disagree, Disagree, Strongly Disagree) and questioned the impact of effective factors on the spectators' attendance in sports played with ball. The second part composed of 10 items which include personal information of the spectators. This questionnaire has evaluated the respondents' comments in four components of economic, charm of the game, spectators' preferences, and facilities.in order to specify the questionnaire validity, the content validity has been used. Therefore, the first questionnaire with 41 items was sent to 8 experienced professors. Then, a list of thirty one items out of forty one were chosen and modified based on the Iranian spectators. Thus, the content validity of the questionnaire was confirmed. Using Cronbach's alpha, the reliability coefficient of the questionnaire in a preliminary study turned out to be 0.86 which is an acceptable and high index of reliability. The collected data was analyzed by using Burlington SPSS software. In order to describe the characteristics of the participants based on mean indices and to analyze inferential statistics, the researchers utilized statistical methods of one-variable $\mathrm{t}$ and $\mathrm{F}$ test of multivariate analysis of variance.

\section{Results}

Table 1. The Characteristics of Research Participants

\begin{tabular}{|l|l|c|c|}
\hline Variable & level & Frequency & Percentage \\
\hline \multirow{4}{*}{ Age } & Young & 20 & $20 \%$ \\
\cline { 2 - 4 } & Teenager & 10 & $10 \%$ \\
\cline { 2 - 4 } & Adult & 70 & $70 \%$ \\
\hline \multirow{5}{*}{ Degree of Education } & junior high school & 10 & $10 \%$ \\
\cline { 2 - 4 } & High School Diploma & 27 & $27 \%$ \\
\cline { 2 - 4 } & Associate's degree & 36 & $36 \%$ \\
\cline { 2 - 4 } & Bachelor's degree & 14 & $14 \%$ \\
\cline { 2 - 4 } & Master's Degree & 10 & $10 \%$ \\
\cline { 2 - 4 } & Ph.D & 3 & $3 \%$ \\
\hline \multirow{3}{*}{ Marital Status } & Single & 24 & $24 \%$ \\
\cline { 2 - 4 } & Married & 76 & $76 \%$ \\
\hline
\end{tabular}




\begin{tabular}{|l|l|c|c|}
\hline Variable & level & Frequency & Percentage \\
\hline \multirow{3}{*}{ Supporters club Member } & Member & 74 & $74 \%$ \\
\cline { 2 - 4 } & Not Member & 26 & $26 \%$ \\
\hline \multirow{3}{*}{ Income Status } & Low & 75 & $75 \%$ \\
\cline { 2 - 4 } & Middle & 15 & $15 \%$ \\
\cline { 2 - 4 } & High & 10 & $10 \%$ \\
\hline \multirow{3}{*}{ Employment Status } & Student & 10 & $10 \%$ \\
\cline { 2 - 4 } & University Student & 39 & $39 \%$ \\
\cline { 2 - 4 } & Unemployment & 41 & $41 \%$ \\
\cline { 2 - 4 } & Employee & 10 & $10 \%$ \\
\hline
\end{tabular}

The data in Table 1 show that among the age conditions the adults have the highest frequency and teenagers have the lowest one. For degree of education, most individuals have associate's degree and the individuals with junior high school have the lowest population. In the case of marital status, the married participants are more than the single ones. The number of subjects who were a member of the supporter club was more than those who were not. The data also indicated that the number of people with low income was more than those who had a good income. For unemployment status, the number of unemployed subjects had the most population and the employees and students had the lowest one.

Table 2. The effect of factors (economic, charm of the game, spectators' preferences, facilities) on the spectators' attendance.

\begin{tabular}{|c|c|c|c|c|c|c|}
\hline Variable & Items & High level & Mean & Std deviation & $\mathrm{t}$ & Level of sig. \\
\hline \multirow{2}{*}{ economy } & Reasonable price of ticket & 1 & $5 / 17$ & 1 & $29 / 43$ & $-0 / 001$ \\
\hline & Not broadcasting volleyball matches on TV & 1 & $1 / 55$ & $0 / 97$ & $35 / 97$ & $0 / 001$ \\
\hline \multirow{9}{*}{$\begin{array}{l}\text { Charm of } \\
\text { the game }\end{array}$} & Good standing of volleyball national team in ranking table & 1 & $3 / 54$ & $0 / 90$ & $36 / 50$ & $0 / 001$ \\
\hline & Good standing of opponent team in ranking table & 1 & $2 / 63$ & $1 / 45$ & $29 / 48$ & $0 / 001$ \\
\hline & Being crucial the results of volleyball national team & 1 & $1 / 67$ & $0 / 34$ & 43 & $0 / 001$ \\
\hline & The existence of star players in the favorite team & 1 & $5 / 79$ & $1 / 39$ & $30 / 91$ & $0 / 001$ \\
\hline & The existence of star players in the opponent team & 1 & $2 / 46$ & $1 / 32$ & $9 / 22$ & $0 / 001$ \\
\hline & Being close and the sensitivity of the game & 1 & $2 / 20$ & $1 / 01$ & $20 / 22$ & $0 / 001$ \\
\hline & Using Offensive Systems by volleyball national team. & 1 & $4 / 59$ & $0 / 94$ & $44 / 62$ & $0 / 001$ \\
\hline & Using defensive Systems by volleyball national team. & 1 & $2 / 03$ & $1 / 27$ & $20 / 25$ & $0 / 001$ \\
\hline & Encourage the spectators of the favorite team & 1 & $3 / 34$ & $1 / 09$ & $26 / 24$ & $0 / 001$ \\
\hline \multirow{13}{*}{$\begin{array}{l}\text { Spectators' } \\
\text { preferences }\end{array}$} & Performing fun and entertainment practices for pregame and between sets. & 1 & $4 / 44$ & $0 / 77$ & $50 / 78$ & $0 / 001$ \\
\hline & $\begin{array}{l}\text { The existence of sufficient advertisement about the time and place of volleyball } \\
\text { national team in media }\end{array}$ & 1 & $2 / 38$ & $0 / 84$ & $45 / 23$ & $0 / 001$ \\
\hline & Holding the matches at the end of the week on Thursday or Friday at 3 p.m. & 1 & $4 / 16$ & $1 / 15$ & $26 / 69$ & $0 / 001$ \\
\hline & Holding the matches at the end of the week on Thursday or Friday at 7 p.m. & 1 & $2 / 27$ & $2 / 76$ & $16 / 38$ & $0 / 001$ \\
\hline & $\begin{array}{l}\text { Holding the matches in one of the days of the week at } 3 \text { p.m. (from Saturday to } \\
\text { Wednesday) }\end{array}$ & 1 & $1 / 39$ & $3 / 38$ & $27 / 48$ & 0/001 \\
\hline & The appropriate condition of weather & 1 & $3 / 32$ & $1 / 19$ & $23 / 55$ & $0 / 001$ \\
\hline & Prevent spectators from verbal abuse and violence & 1 & $3 / 04$ & $3 / 29$ & $45 / 23$ & $0 / 001$ \\
\hline & Member of the fan club of volleyball national team & 1 & $3 / 46$ & $1 / 56$ & $30 / 68$ & $0 / 001$ \\
\hline & \begin{tabular}{|l|l} 
Wearing national team shirts by spectators \\
\end{tabular} & 1 & $2 / 67$ & $0 / 96$ & $9 / 22$ & $0 / 001$ \\
\hline & Going to the hall with friends & 1 & $2 / 43$ & $1 / 29$ & $29 / 34$ & $0 / 001$ \\
\hline & The possibility of attending the hall with family & 1 & $3 / 45$ & $2 / 10$ & $31 / 22$ & $0 / 001$ \\
\hline & Being polite and supporter of hall staff and police force & 1 & $4 / 28$ & $1 / 18$ & $22 / 56$ & $0 / 001$ \\
\hline & The regular holding of the volleyball world league matches & 1 & $4 / 49$ & $1 / 97$ & $37 / 55$ & $0 / 001$ \\
\hline \multirow{7}{*}{ Facilities } & $\begin{array}{l}\text { easy arrival and departure without any time-consuming from the halls and parking } \\
\text { lots }\end{array}$ & 1 & $4 / 73$ & $3 / 06$ & $31 / 70$ & 0/001 \\
\hline & Easy purchase of ticket without standing in long queues. & 1 & $4 / 16$ & $1 / 15$ & $26 / 69$ & $0 / 001$ \\
\hline & $\begin{array}{l}\text { The suitability of the spectators' place in terms of (cleaning, light, visibility to the } \\
\text { ground and seats) }\end{array}$ & 1 & $2 / 97$ & $1 / 31$ & $17 / 64$ & 0/001 \\
\hline & $\begin{array}{l}\text { The existence of healthy buffets having a variety of foods with the quality and } \\
\text { reasonable price }\end{array}$ & 1 & $4 / 55$ & $0 / 85$ & $48 / 38$ & 0/001 \\
\hline & $\begin{array}{l}\text { Easy traffic into the hall (the existence of public transportation system, the Metro, } \\
\text { and special route) }\end{array}$ & 1 & $3 / 81$ & $1 / 51$ & $14 / 18$ & 0/001 \\
\hline & The existence of sufficient parking lots inside or around the hall & 1 & $4 / 71$ & $0 / 72$ & $63 / 61$ & $0 / 001$ \\
\hline & Being a new and modern hall & 1 & $4 / 58$ & $0 / 79$ & $53 / 31$ & $0 / 001$ \\
\hline
\end{tabular}

As the results in Table 2 show, in terms of economic, the reasonable ticket price with the mean of 5.17 led to more 
spectators' attendance; whereas, the live broadcasting of the volleyball national team matches from TV with the mean of 1.55 has the lowest effect in the spectators' attendance. In the case of charm of the game, the existence of star players in the favorite team with the mean of 5.79 had the most effect on the spectators' attendance. Not broadcasting of volleyball matches from TV with the mean of 1.63 and being crucial the results of volleyball national team with the mean of 1.67 had no effect on the spectators' attendance. For spectators' preferences, the regular holding of volleyball world league matches with the mean score of 4.49 had the highest impact on the spectators' attendance. The holding of matches in one of the days of the week at 3 p.m. with the mean score of 1.39 had no effect on the audiences' attendance. In terms of facilities, easy arrival and departure without any time-consuming from the halls and parking lots with the mean score of 4.73 had the highest effect but for the suitability of the spectators' place in terms of (cleaning, light, visibility to the ground and seats) no effect had been observed.

\section{Conclusion}

The results of Table 2 showed that charm of the game, spectators' preferences and the existence of facilities have had a positive impact on the spectators' attendance and just the economic factors had a negative effect on the spectators' attendance at the halls. It has been observed that among the economic factors, the ticket price had a positive effect on the spectators' attendance. In the case of unreasonable ticket price, there is the possibility of decreasing the number of spectators. On the other hand, the lack of matches broadcasting from TV has no effect on the spectators' attendance at the halls. A study by Rivers and Dshryvz (2002) showed that because of being newness, the stadium has attracted more spectators the result of which indicating the importance and necessity of attention to competition venue which can have effective roles in increasing or decreasing the spectators. Amyondyn and Lee (2000) in their study identified the education as one of the important factors in spectators' satisfaction and finally their more attendance. In the field of economic factors, Macpherson et al. (2004) in a study on the factors affecting the spectators' attendance of American Rugby concluded that the reasonable price of ticket has a positive impact on the spectators' attendance at stadium but the lack of broadcasting the matches from TV and season ticket sale has no effect on the spectator attendance (8). The findings of charm of the game also demonstrated that the existence of star players in the favorite team, the existence of star players in opponent team, the good standing of the volleyball national team in ranking table, encourage the spectators of favorite team, close and sensitivity of the match, and using offensive systems by volleyball national team respectively have a positive effect on the spectators' attendance but using defensive systems by volleyball national team and good standing of opponent team in ranking table has no effect on the spectators' attendance in the halls. That is why football leagues of England and Spain are considered as the most popular leagues in the world as stated by Hansen and Gauthier (1992) (5). The obtained results by Ali Mohammadi et al. (2013) indicated that regarding the information and charm of the game factor, there is a significant difference between the spectators of football, basketball, and volleyball premier league. With regard to this factor, Van (2008), Mhas (2004), and Mkdvnaldv et al. (2002) also observed significant differences between different types of sports fields. It seems that the existence of different rules and regulations and the way of holding the different types of sports fields have created distinct differences in terms of charm of watching the volleyball field the results of which correspond to the other studies. The existence of star players in the favorite team leads to the increase both the level of the game and the expectation of the spectators to the star players in their favorite teams. This factor causes the match more beautiful and leads to the good quality of the game and attracts many spectators toward halls to watch a beautiful and admirable match. The findings of spectators' preferences showed that the regular holding of the matches, the existence of fun and entertainment programs in halls, the proper behavior of halls staff and police force, going with friends to the stadium, holding the matches in the appropriate weather, the sufficient advertisement about the time and place of the matches holding in media, holding the competitions in weekends and evening hours, prevent the spectators from violence and verbal abuse, and the possibility of family attendance in halls cause the spectators attend the stadium with more enthusiastic and watch the volleyball matches eagerly. In terms of the spectators' preferences, the regular holding of the volleyball world league competitions has had a positive effect on the spectators' attendance. The research findings clearly demonstrate the importance of the regular holding of the volleyball world league competitions in halls which is undoubtedly the most important concern of our spectators. The volleyball world league schedules are specified before starting the home and away game matches and the game schedules of each team are determined up to the end of the league, and even the spectators can be fully sure to watch the games in halls by getting match tickets. Patton and Burlington (2004) in their study on the spectators of university soccer in the America region 1 concluded that the existence of fun and entertainment programs such as childish games causes people go to the stadiums with their families with the intention of the weekend recreation (9). In term of facilities factors, easy arrival and departure without any time-consuming from the hall and parking lot has had a positive effect on 
the spectators' attendance. As always observed, buying tickets and easy arrival and departure without any timeconsuming from the halls and parking lots in our country are the most important concerns of the spectators. Dvnynhv et al. (2002) in their study have concluded that the various arrivals and departures in stadiums as well as online ticket sales cause spectators go to the stadiums with more enthusiastic (7). These results (except in economic factors) are compatible with the results of Markvm and Stein (1985), Hanson and Gauthier (1992), Shriver and Timothy (1996), Dvnynhv et al. (2002), Chyyang and Lee (2002), Rodney (2003), and Patton and Burlington (2004). These results contradict with the results of Ajdari et al. (2011), Elmiri et al. (2009) (except in economic factors), Loo (2010), and Pace and Zhang (2009). The reason of this contradiction can be due to the difference in statistical population. With regard to the research results, it can be said that considering the factors led to the more spectators' presence at stadiums is of particular importance. The financial factors and sports facilities are of such cases which are in the work scope of sports managers and the people involved. Thus, the more spectators' presence can be provided by improving the halls facilities such as chairs, scoreboard, cleaning, security, the quality of volleyball court, and considering the aesthetic aspects in halls.

\section{References}

Sajjadi, S.N., Omidi, A.R, \& Zare, Gh. (2007). The relationship between the use of sports picture in advertising and the consumed behavior of spectators of sports matches. Movement Journal, volume 34, 83-93.

Alivand, A. (2007). The Sociological examination of factors affecting vandalism and hooliganism in football. M.A. Thesis, Isfahan University.

Fallahi, A. (2008). The Study and prioritize the factors affecting the audiences' presence of Premier League of football matches with the marketing approach. Unpublished Thesis of the Physical education M.A. Tehran University.

A. Michael, s. Levin, (2009). "The Value of Competition: Competitive Balance as a Predictor of Attendance in Spectator Sports," International Journal of Sports Marketing \& Sponsorship.october, pp7-24.

H. Hansen, and r. Gautheir. (1992). "Factors affecting attendance at professional sporting events," Journal of sport management journal of sport management, 3(1), PP 15-32.

H.P. Freiling, (1997). "An analysis of the factors that influence fan attendance in minor league baseball games," Microform publications, international institute for sport and human performance,

M. Donihue, d. Finally, and P. Newberry, (2002). "An analysis of attendance at Major league Baseball spring training games," Journal of sports economics, Vol 8(1), PP 39-61.

T. Macpherson, R. Garland, and K. Haughey, (2000). "Factors that influence Rugby spectator attendance," International sport journal, 2(4), PP 43-53.

R. Patton, and B. Vermont, (2004). "Factors affecting spectator attendance at men NCCA division one soccer games," 7(2), PP 23-33. 